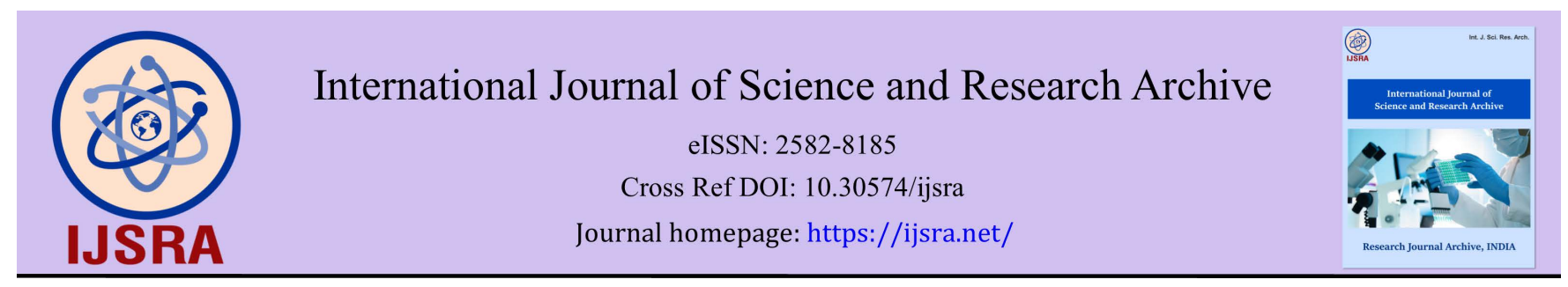

(RESEARCh ARTICLE)

Check for updates

\title{
Comparative evaluation on the effect of selected ergot-derived dopamine on some female reproductive hormones in Wistar rats
}

Tamuno-Boma Odinga ${ }^{1,{ }^{*},}$, Sarah Kelechi Enebeli ${ }^{2}$, Iyingiala Austin-Asomeji ${ }^{3}$, Justice Chindah Ohaka ${ }^{3}$, Popnen Godwin Tee ${ }^{4}$ and Goodluck Nwanyanwu ${ }^{1}$

1 Department of Biochemistry, Faculty of Science, Rivers State University, Nigeria.

${ }^{2}$ Department of Pharmacology, Faculty of Basic Clinical Science, College of Medical Sciences, Rivers State University, Nigeria.

${ }^{3}$ Department of Community Medicine, Faculty of Clinical Sciences, College of Medical Sciences, Rivers State University, Nigeria.

${ }^{4}$ Department of Physiology, Faculty of Basic Clinical Science, College of Medical Sciences, Rivers State University, Nigeria.

International Journal of Science and Research Archive, 2022, 05(01), 103-107

Publication history: Received on 09 January 2022; revised on 14 February 2022; accepted on 16 February 2022

Article DOI: https://doi.org/10.30574/ijsra.2022.5.1.0043

\begin{abstract}
Background: Hormonal imbalance can occur during some disease conditions, while in some other cases, an increase or decrease in the levels of the female hormones in the body might be associated with adverse effects from drugs and may also pose the risk of infertility and Ovarian cancers when these drugs are abused. Although the dopamine agonists have been helpful in ameliorating some disease conditions, it could also cause an adverse effect on the reproductive hormones and other organs of the body.
\end{abstract}

Objective: This study comparatively evaluated the effect of Bromocriptine and Cabergoline on some female reproductive hormones.

Methodology: This study was carried out using twenty-five rats grouped into five groups of five rats in each. Group one was the control group, Group 2 and 3 were low and high dose of Bromocriptine, while Group 4 and 5 were low and high dose Cabergoline. The drugs were administered twenty-four hourly and lasted for 21 days. Blood samples were collected for hormonal assay.

Results: The results for the bioassay of FSH, LH, PROG, PRO and Estrogen revealed that both low and high dose of Bromocriptine and Cabergoline administered to the Wistar rats caused an increase in the concentration of FSH, LH, Progesterone, Prolactin and Estrogen. The level of Prolactin and Estrogen increased significantly at 0.05 level. However, a decrease was observed in prolactin and estrogen level when administered High dose bromocriptine and Low dose cabergoline respectively.

Conclusion: This assessment therefore suggests that both Cabergoline and Bromocriptine had no adverse effects on the female reproductive hormones, however, Cabergoline may pose greater effectiveness than bromocriptine, hence adherence to prescription is necessary for effectiveness.

Keywords: Bromocriptine; Cabergoline; FSH: Follicle stimulating hormone; LH: Luteinizing hormone; PROG: Progesterone; PRO: Prolactin; E: Estrogen

\footnotetext{
${ }^{*}$ Corresponding author: Odinga $\mathrm{T}$

Department of Biochemistry, Faculty of Science, Rivers State University, Nigeria.

Copyright $(2022$ Author(s) retain the copyright of this article. This article is published under the terms of the Creative Commons Attribution Liscense 4.0.
} 


\section{Introduction}

The inappropriate use of drugs has been said to have adverse effect or a harmful and undesired effect on the body as stated by many studies. Ergot-derived dopamine agonists are a group of medicines consisting of bromocriptine, cabergoline, dihydroergocryptine, lisuride and pergolide. They are mainly used for the treatment of Parkinson's disease, either on their own or in combination with other medicines. They are also used to treat conditions including hyperprolactinaemia, prolactinoma and to prevent lactation and migraine [1].

Bromocriptine is an ergot alkaloid and dopamine $\mathrm{D}_{2}$ receptor agonist that has been used to treat Parkinson's disease by affecting dopamine receptor signalling in the nigrostriatal tract and to treat Hyperprolactinemia and Acromegaly through tuberoinfundibular pathways [2]. Bromocriptine demonstrated efficacy as an adjunctive agent in the management of type II diabetes, as well as effects on the cardiac remodeling process, thus has a protective effect on cardiac hypertrophy $[3,4]$.

Cabergoline is a long-acting dopamine-agonist drug that suppresses prolactin secretion and restores gonadal function in women with hyperprolactinemic amenorrhea [5], it is another derivative of the ergot alkaloid with long half-life after oral administration [6]. Cabergoline has been found to suppress cancer progression by reducing angiogenesis and tumour-infiltrating myeloid-derived suppressor cells in vivo [7]. Notable tumour shrinkage until tumour disappearance was observed during Cabergoline treatment in most patients with macroprolactinoma [8], and when assessed in the management of Residual non-functioning pituitary adenoma, it proved to be efficacious in this regard. Cabergoline when tested on hyperprolactinemic infertile women normalized hyperprolactinemia and recovered the ovulatory cycle in all patients. All adenomas contracted, and 11 macroadenomas and 29 microadenomas disappeared [9].

The hormones controlling the female reproductive system are gonadotropin-releasing hormone (GnRH), folliclestimulating hormone (FSH) and luteinizing hormone ( $\mathrm{LH})$, all of which are produced in the brain; Estrogen and progesterone produced by the ovaries and the corpus luteum; and human chorionic gonadotropin (HCG), produced by the placenta during pregnancy [10].

The use of these drugs has been of great advantage; however, some side effects has been reported on the use of these drugs, hence the need to evaluate the effects of the drugs on selected female reproductive hormones and compare the effectiveness of the both drugs on the female reproductive hormones.

\section{Material and methods}

\subsection{Experimental animals}

Twenty-five adults female Wistar rats were obtained from Rivers State University Animal house, Port Harcourt. They were weighed and grouped into five groups based on their body weight, acclimatized for seven days and kept under standard conditions and given standard animal feed and water ad libitum.

All animals were handled in accordance with the Guide for the care and use of laboratory Animals prepared by the National Academy of Sciences and published by the National Institute of Health Guide for the use of Laboratory Animal.

\subsection{Drugs of study}

Bromocriptine (2.5mg tablet) and Cabergoline $(0.5 \mathrm{mg})$ were purchased from a Medical Pharmacy in Port Harcourt, Rivers State, Nigeria for this study.

Experimental grouping/Administration: The adult female Wistar rats were placed into five different groups:

- Group 1 (control): Feed + Water ad libitum

- Group 2: LD Bromocriptine (2.5mg/kg BW) + feed + water

- Group 3: HD Bromocriptine (5mg/kg BW) + Feed + Water

- Group 4: LD Cabergoline $(0.5 \mathrm{mg} / \mathrm{kg}$ BW) + Feed + Water

- Group 5: HD Cabergoline $(1.0 \mathrm{mg} / \mathrm{kg} \mathrm{BW})+$ Feed + Water

The administration was carried out on a twenty-four hourly basis and the mode of administration was done by means of oral galvage and lasted for a duration of twenty-one days. 
(HINT: BW means Body weight, LD means Low dose, HD means High dose)

\subsection{Sample collection}

At the end of the period of administration, the animals were sacrificed, blood samples were collected into plain sample bottles for assay of the female reproductive hormones.

The hormonal assay was carried out using the procedure described in the hormone assay kits according to the principle highlighted for prolactin, progesterone, luteinizing and follicle stimulating hormones [11, 12].

\subsection{Data analysis}

The results obtained were analyzed using SPSS version 25 software for One-way Analysis of Variance, thereafter, the Turkey Post Hoc was done for multiple comparison. The significance level was set at $\mathrm{p}<0.05$

\section{Results}

From the table above, the results for the effect of Bromocriptine and Cabergoline on the levels of the female hormones shows that Bromocriptine and Cabergoline at both high and low doses had significant effect as they increased the LH, FSH, PROG and PRO except low dose Cabergoline which decreased the E2 level at P value 0.05. However, the most increase in comparison to the control group was highest with the animals administered with Bromocriptine than Cabergoline.

Table 1 Effect of Bromocriptine and Cabergoline on selected female reproductive hormones of Wistar rats

\begin{tabular}{|l|c|c|c|c|c|}
\hline Group & FSH $(\mathbf{I U} / \mathbf{m l})$ & $\mathbf{L H}(\mathbf{I U} / \mathbf{m l})$ & Prog $(\mathbf{n g} / \mathbf{m l})$ & Prl $(\mathbf{n g} / \mathbf{m l})$ & $\mathbf{E 2} \mathbf{( p g} / \mathbf{m l})$ \\
\hline Group 1 (Control) & $0.35^{\mathrm{a}} \pm 0.16$ & $0.69^{\mathrm{a}} \pm 0.43$ & $0.75^{\mathrm{a}} \pm 0.12$ & $15.00^{\mathrm{a}} \pm 8.75$ & $69.00^{\mathrm{a}} \pm 8.72$ \\
\hline Group 2 (LDB) & $0.49^{\mathrm{a}} \pm 0.14$ & $1.00^{\mathrm{a} \pm 0.21}$ & $1.52^{\mathrm{a}} \pm 0.17$ & $17.82^{\mathrm{b}} \pm 1.93$ & $81.00^{\mathrm{b}} \pm 7.62$ \\
\hline Group 3 (HDB) & $0.54^{\mathrm{a}} \pm 0.16$ & $1.10^{\mathrm{a}} \pm 0.11$ & $1.67^{\mathrm{a}} \pm 0.08$ & $14.85^{\mathrm{b}} \pm 4.17$ & $76.00^{\mathrm{b}} \pm 8.49$ \\
\hline Group 4 (LDC) & $0.65^{\mathrm{a}} \pm 0.16$ & $1.40^{\mathrm{a}} \pm 0.56$ & $1.54^{\mathrm{a}} \pm 0.67$ & $18.07^{\mathrm{b}} \pm 2.70$ & $66.00^{\mathrm{c}} \pm 4.58$ \\
\hline Group 5 (HDC) & $0.50^{\mathrm{a}} \pm 0.09$ & $1.23^{\mathrm{a}} \pm 0.52$ & $1.66^{\mathrm{a}} \pm 0.07$ & $35.67^{\mathrm{c} \pm} 17.34$ & $111.33^{\mathrm{c}} \pm 2.52$ \\
\hline
\end{tabular}

Values are Mean \pm Standard deviation, Values with the same superscript are not significant at 0.05 level, Values with different superscript are significant at 0.05level (Key: LDB: low dose bromocriptine, HDB: high dose bromocriptine, LDC: low dose cabergoline, HDC: high dose cabergoline, FSH: follicle stimulating hormone, LH: Luteinizing hormone, PROG: progesterone, PRO: prolactin, E2: Estrogen).

\section{Discussion}

The result shown on table 1 revealed the effect of administration of bromocriptine and Cabergoline on the female reproductive hormones in Wistar rats. Bromocriptine caused an increase in the level of follicle stimulating hormone, luteinizing hormone, Estrogen, and significant decrease in the prolactin levels. In women, high FSH level may lead to ovarian hyper stimulation in premenopausal women, with multiple ovarian cysts and a thickened endometrium; this leads to disturbed menstrual cycles [13] i.e., oligomenorrhea or amenorrhea. In women with ovarian failure, both FSH and LH levels rise and this agrees with past research findings [14]. Since LH and FSH are responsible for ovulation and fertility [15], an alteration in the levels of these hormones may adversely affect reproduction in females.

There was a decrease in the level of progesterone upon the administration of high dose Bromocriptine which is in accordance with the findings of other researchers [16], this explains why Bromocriptine is used in the treatment of ovarian cancer because progesterone promotes growth by increasing proliferation, cellular hypertrophy and deposition of extracellular matrix in normal mammary tissue and breast cancer [16].

Cabergoline also caused significant effect on the prolactin levels and this is in line with recent reports [17] where Cabergoline inhibited prolactin secretion, hence this suggests the use of Cabergoline to facilitate the decrease of milk production in lactating mothers and diary ewes.

Low dose Cabergoline caused a decrease in the Estrogen level, this suggests its inhibitory effect on cell growth and hence led to tumor shrinkage [18]. 
Comparing the effects of both drugs in the parameters of study, Cabergoline caused a higher effect as evidenced in the serum concentrations shown in table 1, this suggests it may be more efficacious and produced faster response. This is in line with the study [19] that suggested the effectiveness of Cabergoline than Bromocriptine in controlling symptoms associated with hormone excess, normalizing serum prolactin levels, and shrinking prolactinomas.

\section{Conclusion}

Based on the findings of this study, the various doses of the administered drugs were effective on the studied hormones but Cabergoline was shown to be more effective on the levels of the hormones under study and therefore may pose greater toxicity when abused or not used according to prescriptions.

\section{Compliance with ethical standards}

\section{Acknowledgments}

The authors acknowledge the contributions of Miss Lawrence Chizoba Jessica and Mr. Barine for their contributions.

\section{Disclosure of conflict of interest}

The authors declare no conflict of interest

\section{Statement of ethical approval}

All animals were handled in accordance with the Guide for the care and use of laboratory Animals prepared by the National Academy of Sciences and published by the National Institute of Health Guide for the use of Laboratory Animal.

\section{References}

[1] European Medicines Agency. Article 31 of Directive 2001/83/EC as amended, referral under Community interest. 2008.

[2] Kvernmo T, Härtter S, Burger E. A review of the receptor-binding and pharmacokinetic properties of dopamine agonists.Clinical therapeutics. 2006; 28(8): 1065-1078.

[3] Kerr JL, Timpe EM, Petkewicz KA. Bromocriptine mesylate for glycemic management in type 2 diabetes mellitus. The Annals of pharmacotherapy. 2010; 44(11): 17771785.

[4] Aguayo-Cerón KA, Calzada-Mendoza CC, Méndez-Bolaina E, Romero-Nava R, Ocharan-Hernández ME. The regulatory effect of bromocriptine on cardiac hypertrophy by prolactin and D2 receptor modulation. Clinical and experimental hypertension (New York, N.Y. :1993). 2020; 42(7): 675-679.

[5] Webster J, Piscitelli G, Polli A, Ferrari CI, Ismail I, Scanlon MF. A comparison of cabergoline and bromocriptine in the treatment of hyperprolactinemic amenorrhea. Cabergoline Comparative Study Group. The New England journal of medicine. 1994; 331(14): 904-909.

[6] Nicholas AT, Anne Klibanski. Yen and Jaffe's reproductive endocrinology (8 ${ }^{\text {thedition}) ~ p h y s i o l o g y, ~}$ pathophysiology, and clinical management. Chapter. 2019; 3: 58-74.e8

[7] Hoeppner LH, Wang Y, Sharma A, Javeed N, Van Keulen VP, Wang E, Yang P, Roden AC, Peikert T, Molina JR, Mukhopadhyay D. Dopamine D2 receptor agonists inhibit lung cancer progression by reducing angiogenesis and tumor infiltrating myeloid derived suppressor cells. Molecular oncology. 2015; 9(1): 270-281

[8] Annamaria C, Gaetano L, Lucio A. Cabergoline. Expert Opinion on pharmacotherapy. 2000; 1(3): 555-574.

[9] Masami O, Nobuhiro M, Kosaku A, Takakazu K, Toshiro S, Rena M, Kazue T, Shun ichiro I, Yoshikazu O, Tomokatsu H. Individualized High-Dose Cabergoline Therapy for Hyperprolactinemic Infertility in Women with Micro- and Macroprolactinomas, The Journal of Clinical Endocrinology \& Metabolism. 2010; 95(6): 2672 -2679.

[10] Antenatal care. Hormonal Regulation of the Female Reproductive System. 2022.

[11] Tietz NW. Clinical Guide to Laboratory Tests. 3rd ed., W. B. Saunders Company; Philadelphia. 1995; 1-997. 23.

[12] Uotila M, Ruoslathi E, Envall E. Two-site sandwich enzyme immunoassay with monoclonal antibodies to human alphafetoprotein. J Immunol Methods. 1981; 42: 11-15 
[13] Ardawi MS, Rouzi AA. Plasma adiponectin and insulin resistance in women with polycystic ovary syndrome, Fertility and Sterility. 2005; 83(6): 1708-16.

[14] Mori H, Aisaka K, Kigawa T, Minakuchi H, Sakamoto S. Nihon Sanka Fujinka Gakkaizasshi. 1981; 33(10): 17411748.

[15] Bosch E, Alviggi C, Lispi M, Conforti A, Hanyaloglu AC, Chuderland D, Simoni M, Raine-Fenning N, Crépieux P, Kol S, Rochira V, D'Hooghe T, Humaidan P. Reduced FSH and LH action: implications for medically assisted reproduction. Human reproduction (Oxford, England). 2021; 36(6): 1469-1480.

[16] Lissoni P, Mandalà M, Giani L, Malugani F, Secondino S, Zonato S, Rocco F, Gardani G. Efficacy of bromocriptine in the treatment of metastatic breast cancer- and prostate cancer-related hyperprolactinemia. Neuro endocrinology letters. 2000; 21(5): 405-408.

[17] Caja G, Elhadi A, Such X, Salama A. Suppression of prolactin and reduction of milk secretion by effect of cabergoline in lactating dairy ewes. Journal of dairy science. 2020; 103(12): 12033-12044.

[18] Dall'Ara A, Lima L, Cocchi D, Di Salle E, Cancio E, Devesa J, Müller EE. Inhibitory effect of cabergoline on the development of estrogen-induced prolactin-secreting adenomas of the pituitary. European journal of pharmacology. 1988; 151(1): 97-102.

[19] Arduc A, Gokay F, Isik S, Ozuguz U, Akbaba G, Tutuncu Y, Berker D, Kucukler FK, Aydin Y, Guler S. Retrospective comparison of cabergoline and bromocriptine effects in hyperprolactinemia: a single center experience. Journal of endocrinological investigation. 2015; 38(4): 447-453. 